mouth and throat so as to seriously interfere with his swallowing and bis breathing. The illustration shows very well the condition. An operation had become necessary. On Aug. 1st a long incision was made through the skin from the right ear rearly to the angle of the lef $\mathrm{jaw}$, and the tumour was enucleated in one mass without injury to the mucous membrane of the mouth and throat. The zrowth was somewhat firmly connected with the base of the skull, and it was necessary to plug the upper part of the deep wound in order to check bleeding from a vein which could not be tic d. Very little constitutional disturbance followed, and the patient made a rapid recovery. In consequence of injury to the facial nerve the cornea of the right eye sloughed, and the eye was removed in the following October. The patient was in go'd health till a week ago, when he died at the age of seventy-two years.

Remartis by Mr. PAGE - The case illustrates the uncertainty as to the difficulty in removing these large chronic parotid tumours. Great diffioulty was anticipated in this case, but the tumour shelled out quite readily, and very little blood was lost. The old man, too, bure the operation well.

\section{FYZABAD SADR DISPENSARY.}

A CASE OF CIRSOID ANEURYSM OF THQ SCALP; LIGATURE AND ACUPRESSURE FOLLOWED BY TMMEDIATE AND COMPLETE EXCISION ; RECOVERY.

(Under the care of Sargeon-Major J J. PRATT, I.M S., Civil Surgeon, Fyz ibad.)

CIRsoIn aneurysm is a comparatively rare condition, and its treatment presents great diffizulties to the surgeon. Should the incision invade the diseased tissue the bæmorrhage is so profuse as to endanger the life of the patient and, further, the thinning of the arterial walls often extends mach beyond the apparent swelling, so that the disease is very liable to return and progress after the original mass has been destroyed or removed. The procedure adopted by Surgeon-Major Pcatt promises well to be the best method of treatment, as the preliminary ligature of the supplying arteries prevents any great danger of hæmorrhage during the operation, and the complete excision of the diseased vessels offers the best guarantee against recurrence Mere ligature of the arteries entering the tumour is of very little benefit. It would be of interest to learn the condition of the patient when a longer period has elapsed since the opera. iion.

A Brahman, aged thirty years, was admitted into the dispensary on Jan. 4th, 1897, suffering from a typical cirsoid aneurysm of the left side of the scalp. The arteries affected were the temporal, both anterior and posterior branches, and the occipital. The tumour, which was prominent and lobulated on the surface, occupied practically the whole of the left side of the head above and behind the ear, and was made up of a number of dilated and tortuous arterial branches, the largest of which in their most dilated parts were equal in size to an average forefinger. Pulsation could not be entirely checked by compression of the temporal in front of the ear and the occipital immediately above the nape of the neck, where in its enlarged condition it first became visible. It was consequently evident that to some extent, as was to be expected, the tumour was fed by the supra-orbital and frontal aiteries of the same side and the temporal artery of the opposite side, and, as a matter of fact, on careful examination these were found to be slightly enlarged. A thrill was detected over the centre of the growth and for some distance along the larger feeding vessels. The patient stated that three years ago he noticed a small, rounded swelling on the left side of the top of his head, which pulsated and was painful. It slowly but steadily increased in size until it attained its present dimensions. Four months ago he lost a considerable quantity of blood from it and nearly died. Fearing a recurrence of this mishap he sought surgical aid in the hope of a cure being effected. He was unable to assign any cause for the growth, and could not recollect having sustained any local injury prior to its first appearance. The skin over the most prominent part of the tumour in the posterior parietal region was atrophied and thinned to a dangerous extent and in one spot showed signs of having given way not long before, thus bearing out the truth of the patient's stratement reyarding the hæmorrhage wbi.h had occurred. The case was manifestly one in which immediate operative interference was called for. Accordingly, on the morning of Jan. $7 \mathrm{th}$, the patient, who was in fair condition but decidedly anæmic, was placed under the influence of chloroform, the scalp having first been carefully shaved and cleansed. An incision was made over the left temporal artery immediately in front of the tragus and the vessel at once ligatured. At the other end of the tumour a harelip pin was passed underneath the occipital artery and a ligature tightly applied round it. The pulsation in the tumour was then found to have almost entirely stopped in one or two places only was it faintly perceptible An incision was then made gradually around the whole mass of the tumour, commencing at its posterior border about an inch above the spot where the needle was passed under the occipital artery. Forcipressure was applied in fourteen places in the course of the incision. The tumour was then dissected off the pericranium, ligatures of carbolised catgut were applied round the different bleeding points, and the forceps removed. Three vessels in the pericranium which could not be tied gave considerable trouble; finally, the bleeding from them was arrested in two by acupressure and in the third by the application of a pair of bulldog forceps, both needles and forceps being left $f(r$ the time being in situ. The edges of the wound, which measured five and $a$ half inches in length by a maximum of three and three-quarter inches in breadth, were then brought together as far as possible by harelip pins and sutures, its. surface was swabbed with a solution of perchloride of iron and a compress and bandage were firmly applied. The loss of blood during the operation was considerable, but, taking the nature of the case into consideration, no more than was to be expected. The patient was kept in absolute quiet and rest and on liquid diet. A mixture containing small quantities of quivine and opium was administered with a view to checking the rise of temperature so common in malarial subjects after surgical operations of any kind. The progress of the case was as follows. On the 7th, 8th, and 9 th he was doing well. There was no pain or hæmorrhage. The dressings were left undisturbed. On the 10th the compress and bandage were removed. The surface of the wound in the scalp was covered with iron scab. It was dressed with iodoform and carbolised lint. The incision over the temporal artery had practically healed. The morning temperature was normal, the evening temperature being $100^{\circ} \mathrm{F}$. A saline diaphoretic and laxative mixture was ordered to be given every four hours. On the 11th there was no fever and he was doing well. On the 14th the temperature was normal. Two harelip pins and several sutures were removed. On the 15 th the margins of the wound were granulating. The acupressure needle from beneath the occipital artery and the remaining stitches were removed. On the 17th the progress was maintained. The patient was on fall diet and was putting on flesh. On the 19th the ligature on the temporal artery came away; the wound was contracting. On the $26 \mathrm{th}$ progress had been uninterrupted duing the past week. By Feb. 6 th the wound had become considerably reduced in size and was rapidly healing. There was no pulsation in any ressel in the neighbourhood. The arteries of the front and the opposite side of the scalp had returned to their normal size. On the 22 nd the patient was discharged to the out-patient department with a healthy granulating ulcer of the scalp two and a quarter inches long by one and three-quarter inches broad at the widest part.

Hospital Reform at Bristol.-A meeting of the Hospital Reform Association was held at Bristol on June 16th under the presidency of Dr. Markham E. Skerritt. The discussion which took place brought out the fact that while the medical profession at Bristol are agreed that reform of some sort is necessary, they are not quite unanimous as to the direction in which reform should go. The following resolution, proposed by $\mathrm{Mr}$. Garrett Horder, was passed: "That in the opinion of this meeting it is most desirable that the medical charities of Bristol and Clifton should be restricted as far as possible to the wants of the necessitous poor, and it is further of opinion that the recommendations of the Hospital Reform Association for the prevention of the abuse of the out-patient and casualty departments are deserving of consideration by the governing bodies and acting medical staff of the various hospitals and dispensaries." 